\title{
Fuzzy Logic Controlled Shunt Active Power Filter for Harmonic Compensation and Power Quality Improvement
}

\author{
Aziz Boukadoum ${ }^{1, *}$ and Tahar Bahi ${ }^{2}$ \\ ${ }^{I}$ Department of Electrical Engineering, University of Tebessa, Algeria \\ ${ }^{2}$ Department of Electrical Engineering, University of Annaba, Algeria
}

Received 16 June 2014; Accepted 1 October 2014

\begin{abstract}
In this paper, a shunt active power filter based on fuzzy logic controller is modeled, simulated, and tested. The fundament of Instantaneous Reactive Power Algorithm is used for extracting compensated reference harmonic current. A fuzzy logic controlled shunt Active Power Filter (SAPF) Using Hysteresis Band Current (HBC) is applied to regulate the DC capacitor voltage of (SAPF) in order to improve the active filter dynamic, to ensure sinusoidal source currents and to produce a high power quality. The main goal of the proposed active filtering system is to maintain the THD well within IEEE-519 on harmonics levels. Simulation results through MATLAB/Simulink are presented and interpreted. It is demonstrated that the fuzzy logic controller improves the performance of the active power filter. The implementation of a shunt active power filter has high performance characteristics by using dSPACE system.
\end{abstract}

Keywords: Harmonic, Fuzzy logic, Hysteresis, shunt active power filter, power quality.

\section{Introduction}

The non-linear loads such as power electronic equipments produce harmonics. The harmonic and reactive power cause poor power factor and distort the supply voltage at the common coupling point or customer service point (Zheng ,2009). The international standards recommendation and requirements for harmonic control in electrical power systems imposed some harmonic limits [IEEE Standard,92]. In order to solve this problem, it is necessary to research the alternative solution, Firstly, different configuration are proposed of passive filters have been used to eliminate harmonics current and to compensate reactive power by increasing the power factor. But these filters have the disadvantages of large size; they are ineffective due to their inability to adapt to network parameters characteristic variation, problem of resonance, and deterioration of parameters (Mahalekshmi, 2010). The development of power electronic equipment, since the 1970s environment, active power filters (APFs) was been one of the most competitive modern solutions to suppressing harmonic pollution (Sasaki,2009), enhance power quality, and insure the better power distribution system. According to its procedure connection to the power system, there are two types of (APFs) as series active power filter and parallel (shunt) active power filter (Peng, 1993). Researches and application show that the series active power filter is preferable to compensate the harmonic voltage-source, while shunt active power filter is more suitable to compensate the harmonic current source [Mahalekshmi,10]. This paper present performance improvement of the shunt active power filter that consists of three principal parts, namely, the voltage source inverter, $D C$ energy storage device $(C f)$ and coupling inductance $(L f)$. The inverter having six IGBTs switches is used to charge and to discharge the capacitor voltage source in order to provide the required compensation current, the capacitor voltage source is used to store energy and the inductance is used to smoothen the ripple of the harmonic current injected by shunt active power filter. The input supply voltage source provides the required active power and the capacitor voltage source of shunt active power filter provides the reactive power for the load. The load is a three-phase full-bridge diode rectifier supplying a RL load, shown as (Fig. 1).

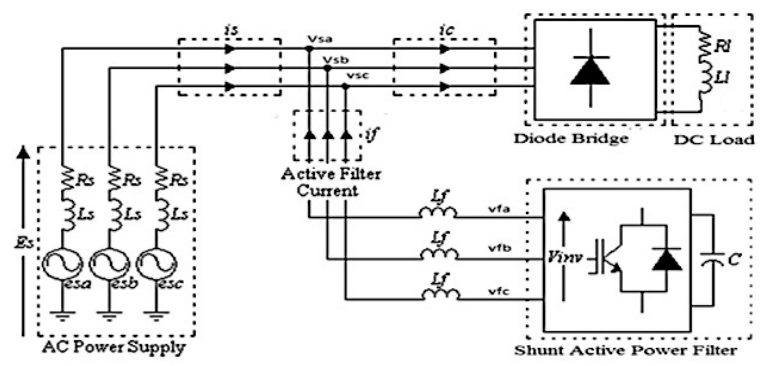

Fig. 1. Three-phase Shunt Active Power Filter system

The basic equations of the shunt active filter and the system are as follows: 


$$
\left\{\begin{array}{l}
v_{s a}=v_{f a}+R_{f} i_{f a}+L_{f} \frac{d i_{f a}}{d t} \\
v_{s b}=v_{f b}+R_{f} i_{f b}+L_{f} \frac{d i_{f b}}{d t} \\
v_{s c}=v_{f c}+R_{f} i_{f c}+L_{f} \frac{d i_{f c}}{d t}
\end{array}\right.
$$

\section{Instantaneous Reactive Power Theory}

Instantaneous Reactive Power algorithm in time domain (Akagi, 1983), (Peng, 1993), can be used to identify the reference harmonic currents. offers the advantage to choosing the disturbance harmonics with precision, speed and ease implementation. The first step of this method to transforming the three phase $(\mathrm{a}, \mathrm{b}, \mathrm{c})$ voltages and currents to two-phase $\alpha, \beta$, using the Direct Conversion of Concordia, and $(\mathrm{d}, \mathrm{q})$ By using Park transformation. The principle adjustment of this method is to extract the fundamental component and harmonic removed component using low pass filters ( LPF). We want to use the synchronous reference frame-based method for controlling the active filter.

In this method, first, the load current and source voltage are given by the following equations:

$$
\begin{aligned}
& {\left[\begin{array}{l}
i_{L \alpha} \alpha \\
i_{L \beta} \\
i_{0}
\end{array}\right]=\sqrt{\frac{2}{3}} \cdot\left[\begin{array}{ccc}
1 & 2 & 3 \\
0 & \frac{\sqrt{3}}{2} & -\frac{\sqrt{3}}{2} \\
\frac{1}{\sqrt{2}} & \frac{1}{\sqrt{2}} & \frac{1}{\sqrt{2}}
\end{array}\right] \cdot\left[\begin{array}{c}
i_{L a} \\
i_{L b} \\
i_{L c}
\end{array}\right]} \\
& {\left[\begin{array}{c}
v_{\alpha} \\
v_{\beta} \\
v_{0}
\end{array}\right]=\sqrt{\frac{2}{3}} \cdot\left[\begin{array}{ccc}
1 & \frac{2}{\sqrt{3}} & -\frac{3}{2} \\
0 & \frac{\sqrt{3}}{2} \\
\frac{1}{\sqrt{2}} & \frac{1}{\sqrt{2}} & \frac{1}{\sqrt{2}}
\end{array}\right] \cdot\left[\begin{array}{l}
v_{a} \\
v_{b} \\
v_{c}
\end{array}\right]}
\end{aligned}
$$

The instantaneous real and imaginary power can be expressed by the following system:

$$
\left[\begin{array}{l}
p \\
q
\end{array}\right]=\left[\begin{array}{cc}
v_{\alpha} & v_{\beta} \\
-v_{\beta} & v_{\alpha}
\end{array}\right] \cdot\left[\begin{array}{l}
i_{\alpha} \\
i_{\beta}
\end{array}\right]
$$

The instantaneous real and imaginary power can be decomposed into two AC and DC parts. The DC part resulted from the fundamental current and voltage and the $\mathrm{AC}$ part resulted from the harmonics:

$$
\begin{aligned}
& p=\bar{p}+\widetilde{p} \\
& q=\bar{q}+\widetilde{q}
\end{aligned}
$$

$\bar{p}, \bar{q}:$ DC average value of the instantaneous real and imaginary power respectively, its corresponds to the resulted from the fundamental current and voltage from the power source to the load.

$\widetilde{p}, \widetilde{q}:$ AC value of the instantaneous real and imaginary power respectively, it does not have average value, and is related to the harmonic currents and voltage from the power source to the load.

The references currents are calculated by the following expression:

$\left[\begin{array}{l}i_{\alpha} \\ i_{\beta}\end{array}\right]=\frac{1}{v_{\alpha}^{2}+v_{\beta}^{2}}\left[\begin{array}{cc}v_{\alpha} & -v_{\beta} \\ v_{\beta} & v_{\alpha}\end{array}\right] \cdot\left[\begin{array}{l}p \\ q\end{array}\right]$

With:

$\left[\begin{array}{l}i_{\alpha} \\ i_{\beta}\end{array}\right]=\frac{1}{\Delta}\left[\begin{array}{cc}v_{\alpha} & -v_{\beta} \\ v_{\beta} & v_{\alpha}\end{array}\right] \cdot\left[\begin{array}{l}\bar{p} \\ 0\end{array}\right]+\frac{1}{\Delta}\left[\begin{array}{cc}v_{\alpha} & -v_{\beta} \\ v_{\beta} & v_{\alpha}\end{array}\right] \cdot\left[\begin{array}{c}0 \\ \bar{q}\end{array}\right]+\frac{1}{\Delta}\left[\begin{array}{cc}v_{\alpha} & -v_{\beta} \\ v \beta & v_{\alpha}\end{array}\right] \cdot\left[\begin{array}{l}\tilde{p} \\ \tilde{q}\end{array}\right]$

Here,

$\Delta=v_{\alpha}^{2}+v_{\beta}^{2}$

The reference current results based on the instantaneous real and imaginary power should be determined according to the flowing equation:

$\left[\begin{array}{c}\tilde{i}_{\alpha} \\ \widetilde{i}_{\beta}\end{array}\right]=\frac{1}{v_{\alpha}^{2}+v_{\beta}^{2}}\left[\begin{array}{cc}v_{\alpha} & -v_{\beta} \\ v_{\beta} & v_{\alpha}\end{array}\right] \cdot\left[\begin{array}{l}\tilde{p} \\ \widetilde{q}\end{array}\right]$

Finally, we can calculate the reference harmonic current as:

$$
\left[\begin{array}{l}
i_{a}^{*} \\
i_{b}^{*} \\
i_{c}^{*}
\end{array}\right]=\sqrt{\frac{2}{3}} \cdot\left[\begin{array}{cc}
1 & 0 \\
-\frac{1}{2} & \frac{\sqrt{3}}{2} \\
-\frac{1}{2} & -\frac{\sqrt{3}}{2}
\end{array}\right] \cdot\left[\begin{array}{c}
\widetilde{i}_{\alpha} \\
\widetilde{i}_{\beta}
\end{array}\right]
$$

The diagram bloc of instantaneous reactive power is shown as (Fig. 2).

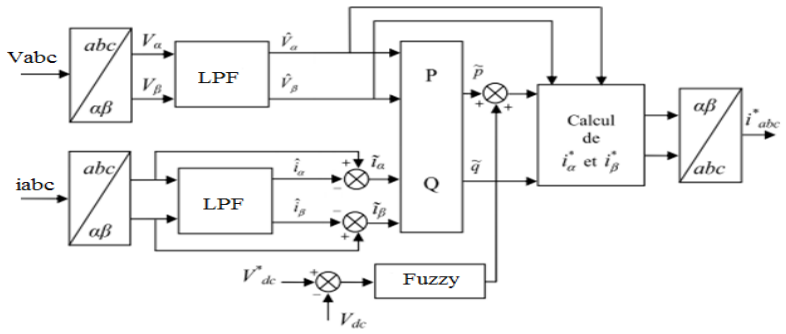

Fig. 2. Instantaneous Reactive Power Algorithm 
The hysteresis band current control scheme, used for the control of shunt active power filter line current (Boukadoum ,2013), is shown in (Fig. 3).

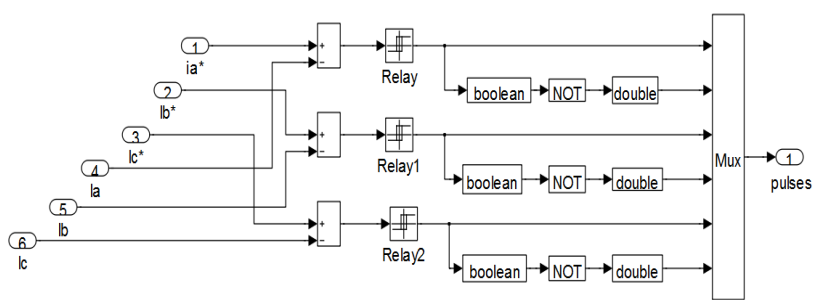

Fig. 3. Hysteresis band current control

\section{Control of de bus voltage source}

The advantage control of DC voltage source of shunt active power filter arises suitable transit of supply power necessary added to power active fluctuate. The storage capacity $\mathrm{C}$ absorbs the power fluctuations caused by the compensation of the reactive power. In the normal conditioner, the real power supplied by the source should be equal to the real power demand of the load plus a small power to compensate the losses in the active filter (Rathika, 2010). Thus, the DC capacitor voltage can be kept at constant value and confirmed at a reference value. However, in the abnormal conditioner, In the presence of harmonics current, when the load changes, the real power balance between the source and the load will be disturbed. In this case, the real power poured most be compensated by the DC capacitor of inverter constructor of (SAPF). The changes of DC capacitor voltage from its reference most is regulate. 4

\section{A. Fuzzy logic controller}

A fuzzy logic controller is based on a collection of control rules governed by the compositional rule of inference applied to maintain the constant voltage across the capacitor by minimizing the error between the capacitor voltage and it's reference voltage [Rathika , 10], the block diagram of a such control is illustrated by the (fig. 4).

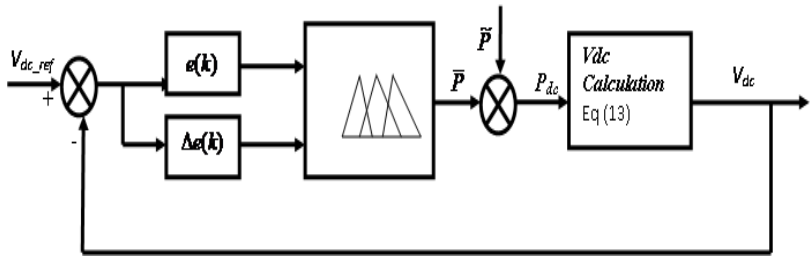

Fig. 4. Control of de voltage source of SAPF

A fuzzy logic controller (FLC) converts is advanced control strategy (Mekri, 2007), (Hamadi, 2004) the based fuzzy rules are constructed by expert experience or knowledge database. In the input of (FLC), the error e (k) and the Change of error $\Delta \mathrm{e}(\mathrm{k})$ have been placed of the angular velocity to be the input variables of the fuzzy logic controller. Then the output variable of (FLC) the fuzzy logic controller is presented by the control voltage $\mu(\mathrm{k})$, the type of fuzzy inference engine used is Mamdani. The linguistic input variables are defined as $(\mathrm{N}, \mathrm{Z}, \mathrm{P}$,) which, negative, zero, and positive respectively. In The output the linguistic variables are defined as (PB, PM, PS) which, positive big, positive mean and, positive small zero respectively. The fuzzy rules are summarized in (Table 1).
Table 1. Rule base table

\begin{tabular}{|l|l|l|l|l|l|}
\hline$\Delta e(k)$ & $\mathrm{NB}$ & $\mathrm{NS}$ & $\mathrm{Z}$ & $\mathrm{PS}$ & $\mathrm{PB}$ \\
\hline $\mathrm{N}$ & & & & & \\
\hline $\mathrm{Z}$ & $\mathrm{PB}$ & $\mathrm{PS}$ & $\mathrm{PS}$ & $\mathrm{Z}$ & $\mathrm{NB}$ \\
\hline $\mathrm{P}$ & PB & PS & $\mathrm{Z}$ & $\mathrm{NS}$ & $\mathrm{NB}$ \\
\hline
\end{tabular}

The real power absorbed by DC voltage can be given by:

$$
p_{d c}=\frac{d}{d t}\left(\frac{1}{2} c_{d c} \cdot v_{d c}^{2}\right)
$$

For few variation value of DC voltage around its reference, we have:

$$
p_{d c}=c_{d c} \cdot v^{*} d c \cdot \frac{1}{2} \cdot \frac{d}{d t}\left(v_{d c}\right)
$$

After, The use of Laplace transform :

$$
v_{d c}(s)=\frac{2 \cdot p_{d c}(s)}{v^{*} d c \cdot c_{d c} \cdot s}
$$

The transfer function is defined:

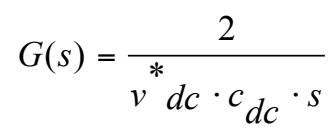

The instantaneous error $\mathrm{e}(\mathrm{k})$ between ${ }^{v} d c$ and its reference $v^{*} d c$ is given by:

$e(k)=v_{d c}(k)_{r e f}-v * d c(k)$

The change of the error can be calculated by:

$$
\Delta e(k)=e(k)-e(k-1)
$$

The output of the fuzzy logic controller system is the change of the maximum current $\mu(k)$, the Product block outputs $P(k)$ is the result of multiplying of the error dc voltage $e(k)$ and the output maximum current of FLC, obtained according to following equation:

$$
P(k)=\mu(k) \cdot \Delta e(k)
$$

The membership functions of the fuzzy logic controller are shown in (Fig. 5. a, b). 


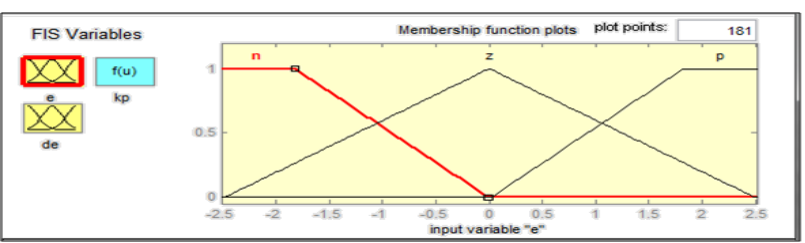

(a)

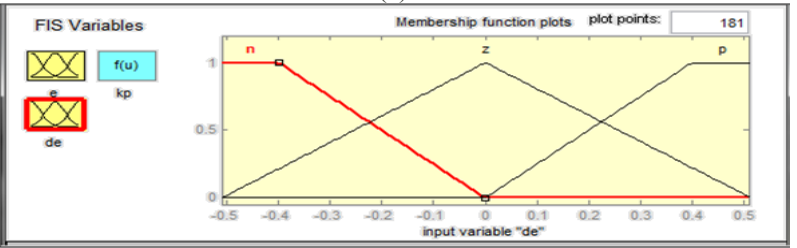

(b)

Fig. 5. Input membership function

\section{Simulation and experimental results}

Simulations and experimental results are performed in a laboratory prototype to confirm the validity of the proposed control scheme. Simulations test is performed to confirm the validity of the proposed system. The shunt active power filter was examined through simulations Matlab/Simulink. All spectrum analysis harmonic figures are below the levels imposed by international standards recommendation IEEE 519-1992, in terms of total distortion harmonic (THD). The parameters of the simulated system are shown in (Table 2).

Table 2. System Parameters

RMS supply phase voltage source $50 \mathrm{~V}, 50 \mathrm{~Hz}$

\begin{tabular}{ll}
\hline Source impedance & $\mathrm{R}=0.1 \Omega, \mathrm{L}=0.5 \mathrm{mH}$ \\
\hline Load rectifier bridge & $\mathrm{R}=45 \Omega, \mathrm{L}=50 \mathrm{mH}$ \\
\hline inverter DC bus voltage & $140 \mathrm{~V}$
\end{tabular}

(Fig. 6) Shows the line current distorted due to the presence of harmonics.

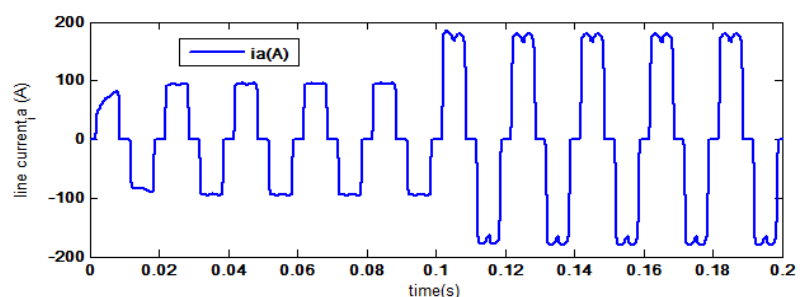

Fig. 6. Line current (uncompensated)

In this case, the spectrum harmonics analysis, where the THD is $26.52 \%$, that is far the limit of the harmonic standard, shown as (Fig. 7).

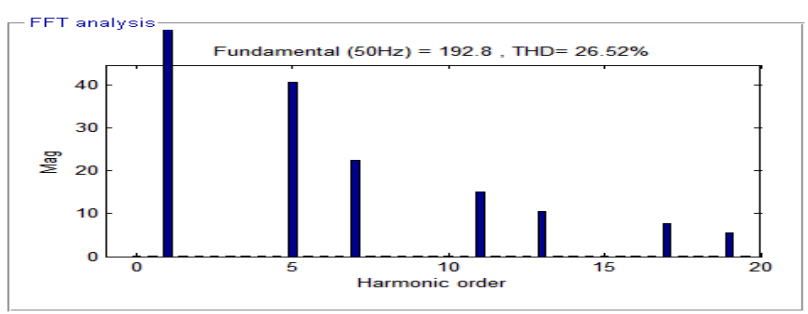

Fig. 7. Spectrum Harmonics (uncompensated)

The reference compensation harmonic currents can be seen in (Fig. 8). the spectrum harmonics analysis can be seen in (Fig. 9), which contains the $5^{\text {th }}, 7^{\text {th }}, 11^{\text {th }}, 13^{\text {th }}$ and etc.

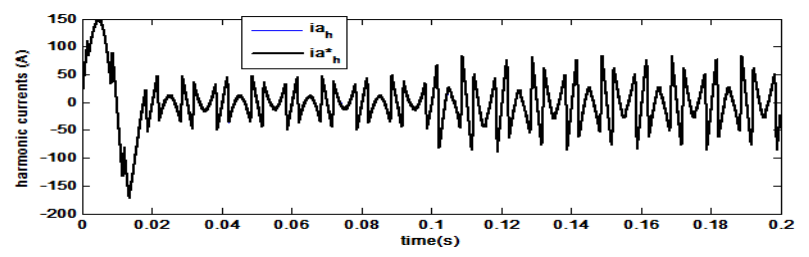

Fig. 8. The reference harmonic currents

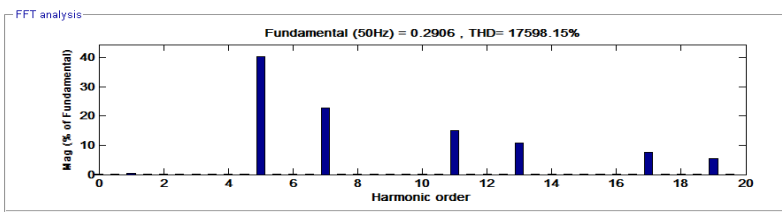

Fig. 9. Harmonic spectrum of compensate harmonics current

The filtering result can be seen in (Figs. 9 and 10). The line current is sinusoidal and the THD decreases to $0.84 \%$ before harmonic compensation that is within the limit of the harmonic standard.

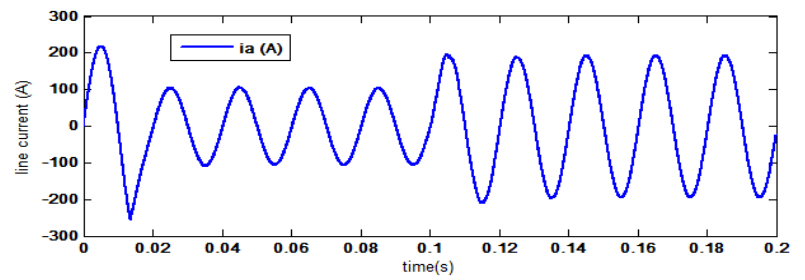

Fig. 9. Line current (compensated)

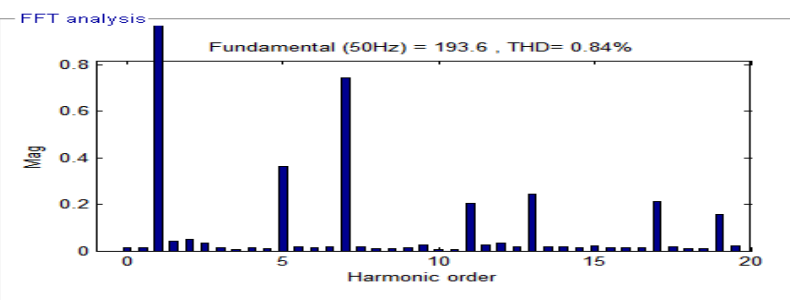

Fig. 10. Spectrum Harmonics Analysis (compensated)

(Fig. 11,a,b) shows the line current and the input voltage waveforms. to verify that they are in phase.
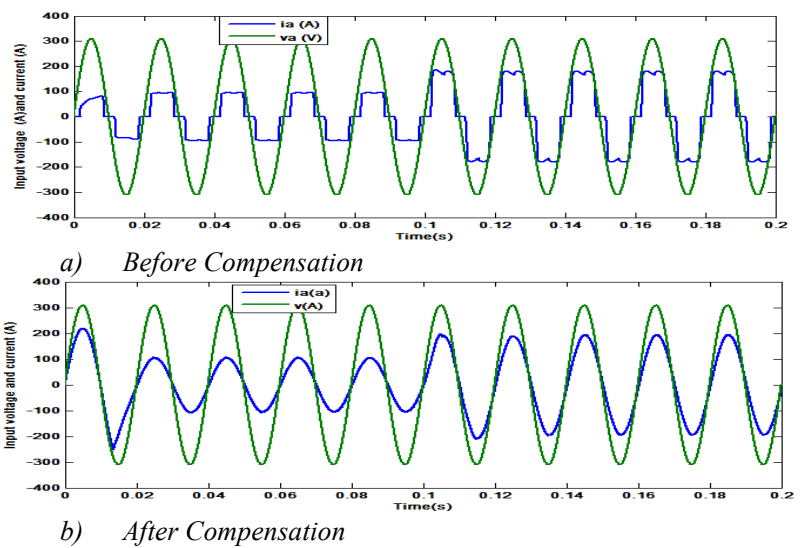
Fig. 11. Line current and input voltage waformes

The (fig. 12) shows the DC capacitor voltage; We can see that its value follows up its reference at $840 \mathrm{~V}$. we have changed the reference value in $\mathrm{t}=0.1 \mathrm{~s}$ at $750 \mathrm{~V}$, the capacitor voltage source pursue its reference. that is the objective of fuzzy logic controller.

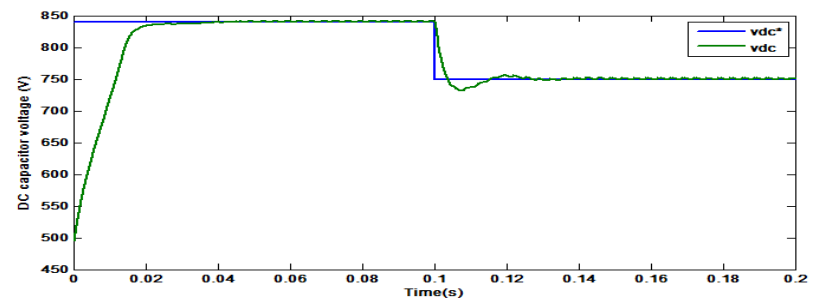

Fig. 12. The DC capacitor voltage regulation bloc of a shunt active power filter

(Fig. 13), presents the evolution of the instantaneous three-phase active and undesirable consumable reactive power without SAPF.

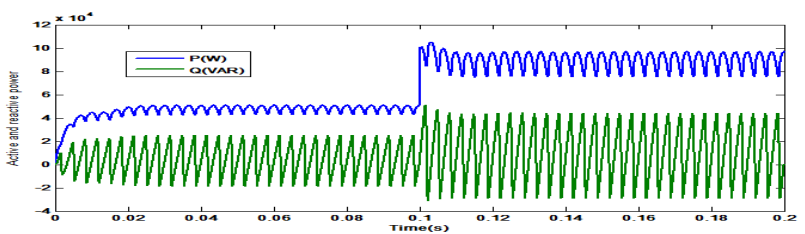

Fig. 13. Instantaneous active and reactive power (without SAPF)

(Figs. 14 and 15) present the waveform of the instantaneous three-phase active, reactive power and power factor correction with the use of SAPF. We can seen, that the power active and reactive and power factor also improved.

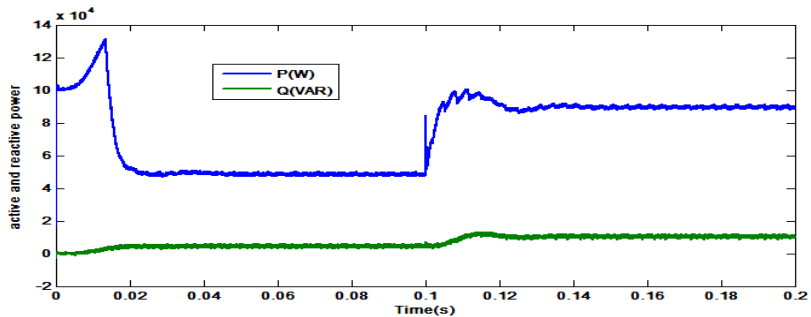

Fig. 14. Instantaneous active and reactive power after compensation (with SAPF)

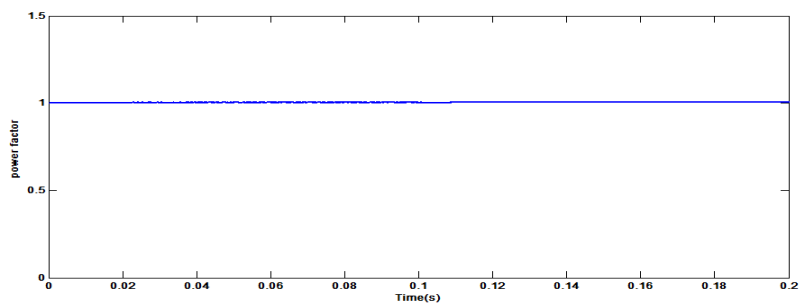

Fig. 15. Power factor correction (unit factor)

In all studied cases we observe that the DC link follows its reference and the line current is sinusoidal with a unit factor, this means that the control is robust.
The experimental tests have been focused on the validation of the proposed SAPF control. The used experimental equipments, installed in the laboratory of the Setif University, Algeria, in (fig.16) a photo of the experimental setup is shown.

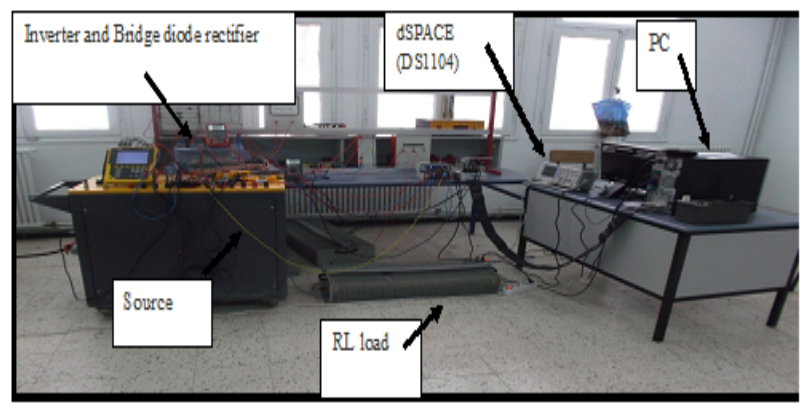

Fig. 16. Experimental setup

Using power quality analysis, (Fig. 17), shows the line distortion current and voltage waveforms, illustrate in figure 18 we can see the spectrum harmonic currents analysis when the SAPF is not working Shawn as (fig. 19). The same comment can be observed in different phase between current and voltage and the THD of the line current is $25.6 \%$. The effectiveness of the SAPF, which can be observed in Fig. 20, that shows the input voltage and line currents waveforms are sinusoidal and in phase, the THD of current decreases at $5.5 \%$, shown as (fig. 21 ).

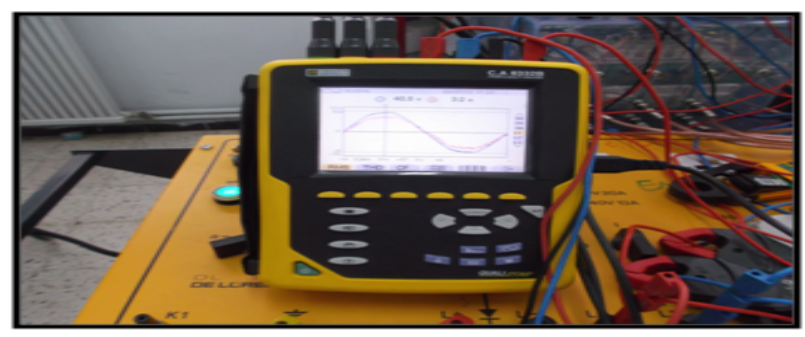

Fig. 17. Extracted of Input voltage and input current

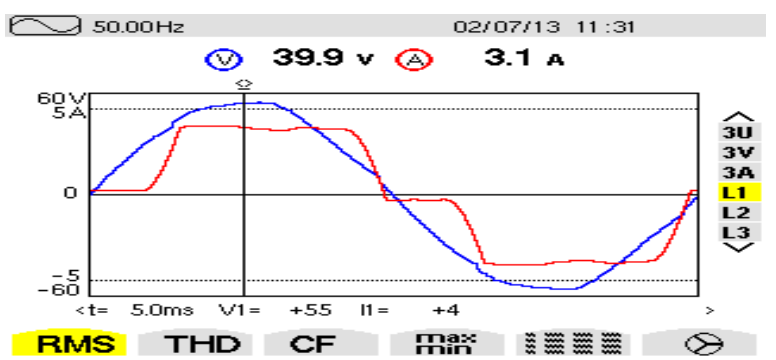

Fig. 18. Line current and voltage before compensation

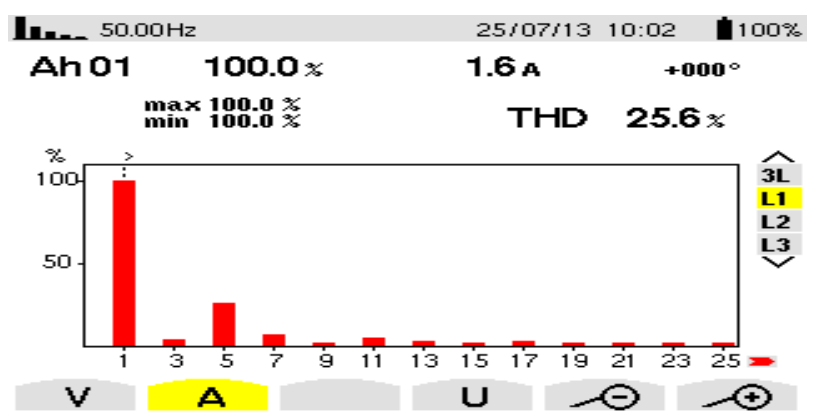




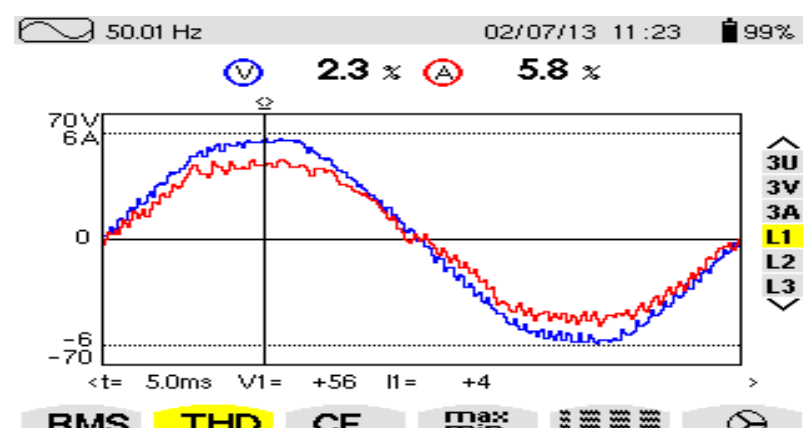

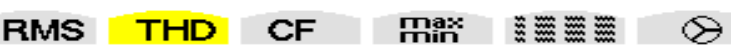

Fig. 20. Line current and voltage after compensation

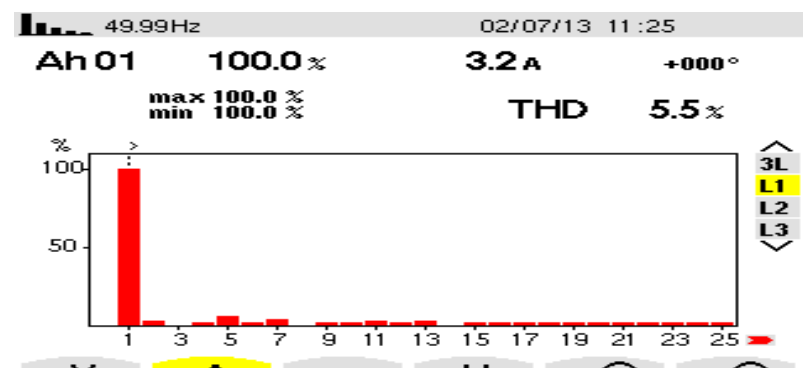

Fig. 21. Spectrum Harmonics measurement (compensated)

(Fig. 22, and 23), illustrates the energetic statistic measured of active, reactive and apparent power of proposed system with and without SAPF, using power quality analysis, Shawn as fig. 22. We can see that the reactive is reduced at 11.7 VAR compared to initialed value 42.4 VAR.

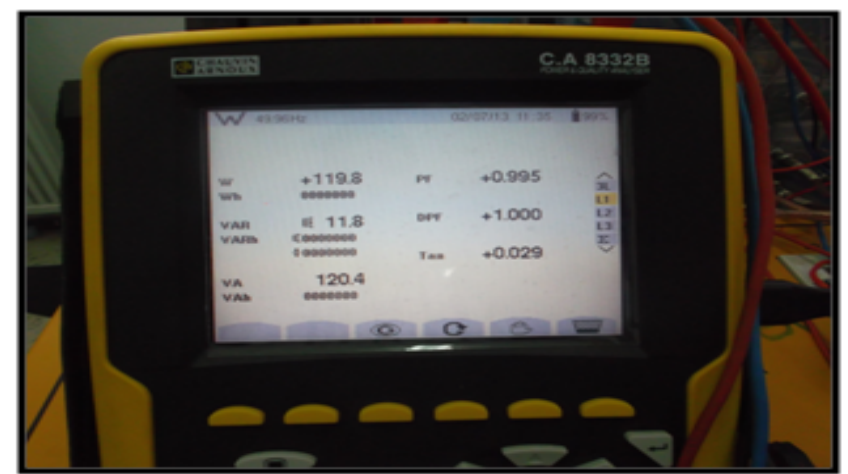

Fig. 22. Extracted of powers

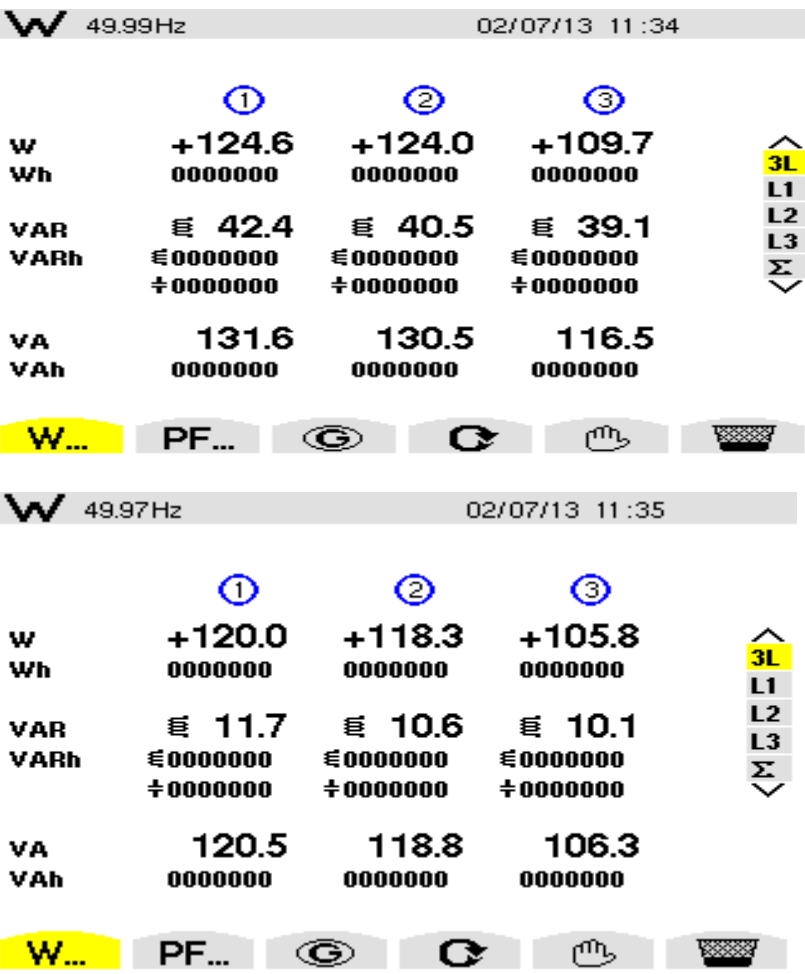

Fig. 23. Active, reactive and apparent power measurements with SAPF

\section{Conclusion}

We introduce to shunt active power filter. Fuzzy logic controller is used to regulate DC link capacitor voltage and to compensate harmonic current. Using dSPACE system, the implemented shunt active power filter has high performance characteristics. The input currents are sinusoidal waveforms with a unit factor. The total harmonic distortion (THD) has been reduced clearly, that is within the limit of the harmonic standard recommendation of IEEE 519-1992 on harmonics level. The compared to the conventional system, simulation results analysis reveal that the shunt active power filter performs perfectly in conjunction with fuzzy logic controller. Experimental results are introduced to validate the proposed system.

\section{References}

[1]. (Akagi, 1983) H. Akagi, Y. Kanazawa and A. Nabae, « Generalized theory of the instantaneous reactive power in threephase circuits ». Proceeding International Power Electronics Conference.Tokyo, Japan, pp. 1375-1386, (1983).

[2]. (Boukadoum ,2013])A. Boukadoum, T. Bahi, A. Bouguerne, Y. Soufi, S. Oudina" Hysteresis Band Current and Fuzzy Logic Control for Active Power Filter » Monaco Développement Durable (MC2D) \& MITI, Organise the Seventh International Conference and Exhibition on Ecological Vehicles and Renewable Energies. 2013.

[3]. (Chennai , 2011) S. Chennai and M. T. Benchouia "'Intelligent Controllers for Shunt Active Filter to Compensate Current Harmonics Based on SRF and SCR Control Strategies "'
International Journal on Electrical Engineering and Informatics, Vol ume 3, Number 3, 2011.

44]. (Dehini, 2009) R. Dehini, A. Bassou, B.Ferdi "' Artificial Neural Networks Application to Improve Shunt Active Power Filter ", World Academy of Science, Engineering and Technology 332009.

[5]. (Gyugyi, 1976) L. Gyugyi and E. Strycula, "Active AC power filters”, in Conf. Rec. IEEE-IAS Annu. Meeting, 1976, pp. 529535.

[6]. (Hamadi, 2004) A. Hamadi and K. Al-Haddad, P.J. Lagact and A. Chandra "' Indirect current control techniques of Three Phase APF Using Fuzzy Logic and Proportional Integral Controller: Comparative analysis "' 0-7803-8746-5/04/\$20.00 02004 IEEE. 
[7]. [IEEE Standard,92] IEEE Standard 519-1992, \IEEE recommended practices and requirements for harmonic control in electrical power systems," IEEE Std 519-1992, 12 April.1993.

[8]. (Mahalekshmi,2010) T. Mahalekshmi "' Current Harmonic Compensation and Power Factor Improvement by Hybrid Shunt Active Power Filter " International Journal of Computer Applications (0975 - 8887) Volume 4 - No.3, July 2010.

[9]. (Mekri, 2007) F. Mekri, M. Machmoum , B. Mazari , N. Ait Ahmed "Determination of Voltage References for Series Active Power Filter Based on a Robust PLL System " 1-4244-0755-9/07/\$20.00 '2007 IEEE

[10]. (Peng, 1993) F. Z. Peng, H. Akagi, and A. Nabae, "Compensation characteristics of the combined system of shunt passive and series active filters," IEEE'Trans. Industry Applications, Vol. 29, No.1, pp. 144-152,1993.

[11]. (Rathika ,2010) P. Rathika and Dr. D. Devaraj " Fuzzy Logic Based Approach for Adaptive Hysteresis Band and Dc Voltage Control in Shunt Active Filter " O International Journal of Computer and Electrical Engineering, Vol. 2, No. 3, June, 2010, 1793-8163.

[12]. (Sasaki,2009) H. Sasaki \& T. Machida, "A new method to eliminate AC harmonic currents by magnetic flux compensationconsiderations on basic design", IEEE Trans. Power Appl. Syst., vol. PAS-90, No. 5, pp. 2009-2019, Jan. 1971.

[13]. (Zheng ,2009) Z. Zheng and W. Cong, "' Measures of Suppressing Harmonic Pollution generated by Power Electronic Equipment ", National Science Foundation under Grant 2008A470004 University of Mining and Technology Beijing, China. IEEE. 2009. 